\title{
Sustained acoustic medicine for the treatment of musculoskeletal injuries: a systematic review and meta-analysis
}

\author{
Sandra L. Winkler ${ }^{1}$, Anthony E. Urbisci ${ }^{1}$ and Thomas M. Best ${ }^{2 *}$
}

\begin{abstract}
Background: Musculoskeletal injuries account for 10 million work-limited days per year and often lead to both acute and/or chronic pain, and increased chances of re-injury or permanent disability. Conservative treatment options include various modalities, nonsteroidal anti-inflammatory drugs, and physical rehabilitation programs. Sustained Acoustic Medicine is an emerging prescription home-use mechanotransductive device to stimulate cellular proliferation, increase microstreaming and cavitation in situ, and to increase tissue profusion and permeability. This research aims to summarize the clinical evidence on Sustained Acoustic Medicine and measurable outcomes in the literature.

Methods: A systematic literature review was conducted using PubMed, EBSCOhost, Academic Search Complete, Google Scholar and ClinicalTrials.gov to identify studies evaluating the effects of Sustained Acoustic Medicine on the musculoskeletal system of humans. Articles identified were selected based on inclusion criteria and scored on the Downs and Black checklist. Study design, clinical outcomes and primary findings were extracted from included studies for synthesis and meta-analysis statistics.
\end{abstract}

Results: A total of three hundred and seventy-two participants (372) were included in the thirteen clinical research studies reviewed including five (5) level I, four (4) level II and four (4) level IV studies. Sixty-seven (67) participants with neck and back myofascial pain and injury, one hundred and fifty-six (156) participants with moderate to severe knee pain and radiographically confirmed knee osteoarthritis (Kellgren-Lawrence grade II/III), and one hundred forty-nine (149) participants with generalized soft-tissue injury of the elbow, shoulder, back and ankle with limited function. Primary outcomes included daily change in pain intensity, change in Western Ontario McMaster Osteoarthritis Questionnaire, change in Global Rate of Change, and functional outcome measures including dynamometry, grip strength, range-of-motion, and diathermic heating (temperature measurement).

Conclusion: Sustained Acoustic Medicine treatment provides tissue heating and tissue recovery, improved patient function and reduction of pain. When patients failed to respond to physical therapy, Sustained Acoustic Medicine proved to be a useful adjunct to facilitate healing and return to work. As a non-invasive and non-narcotic treatment option with an excellent safety profile, Sustained Acoustic Medicine may be considered a good therapeutic option for practitioners.

\section{Key points}

*Correspondence: txb440@med miamiedu

${ }^{2}$ UHealth Sports Medicine Institute, University of Miami, Coral Gables, FL, USA

Full list of author information is available at the end of the article
- The significant and clinically meaningful reduction in musculoskeletal pain (1.96-3.94 points, $0-10$ point pain scales) and improvement in joint function original author(s) and the source, provide a link to the Creative Commons licence, and indicate if changes were made. The images or other third party material in this article are included in the article's Creative Commons licence, unless indicated otherwise in a credit line to the material. If material is not included in the article's Creative Commons licence and your intended use is not permitted by statutory regulation or exceeds the permitted use, you will need to obtain permission directly from the copyright holder. To view a copy of this licence, visit http://creativecommons.org/licenses/by/4.0/. The Creative Commons Public Domain Dedication waiver (http://creativeco mmons.org/publicdomain/zero/1.0/) applies to the data made available in this article, unless otherwise stated in a credit line to the data. 
(20-87\%) were reported in $\mathrm{n}=9$ and $\mathrm{n}=6$ studies, respectively on Sustained Acoustic Medicine.

- In addition to measurable clinical outcomes reported in the literature, $\mathrm{n}=2$ studies reported on vigorous therapeutic heat $\left(\Delta 4{ }^{\circ} \mathrm{C}\right.$ to $\left.\Delta 12{ }^{\circ} \mathrm{C}\right)$ and $\mathrm{n}=1$ study on biological clearance of lactic acid from Sustained Acoustic Medicine treatment in human participants.

- Clinical evidence, health economic cost effectiveness and health provider positive opinions on Sustained Acoustic Medicine support treatment utilization in musculoskeletal conditions such as Osteoarthritis, tendinopathy, and myofascial pain.

\section{Introduction}

Musculoskeletal pain is a common issue experienced by most of the general population at some point over the lifetime [1]. Chronic musculoskeletal pain affects $20-33 \%$ of the world population, approximately 1.71 billion people [2]. Musculoskeletal pain is defined as acute or chronic pain affecting bones, muscles, tendons, ligaments, and nerves. Chronic pain can significantly affect daily activities, quality of life while promoting disability resulting in staggering health costs. It is estimated that the US spends $\$ 240$ billion annually on musculoskeletal pain-related medical care. Back pain is the most common musculoskeletal pain [3-5]. Approximately 70-80\% of Americans will experience back pain in their lifetime. Back pain is the fifth leading cause of hospitalization [4, 5]. Chronic musculoskeletal pain is most common in the older population. Osteoarthritis, a significant cause of joint pain, affects more than one-third of people above age 60 [6]. Musculoskeletal pain is also highly prevalent in athletes and military personnel dealing with strains, sprains, and fractures [7].

Musculoskeletal pain can be caused by a variety of conditions including maximal or submaximal concentric contractions, joint contractures, and direct trauma, leading to the abnormal release of acetylcholine resulting in increased tension, blood flow restriction, inflammation, and tissue damage [8-13]. A combination of pharmacological and nonpharmacological intervention is used to treat musculoskeletal pain $[14,15]$. Typical pharmacological regimens include nonsteroidal antiinflammatory drugs (NSAIDs), opioids, and adjunctive analgesics. The long-term use of NSAIDs has adverse systemic effects [16-19]. The use of opioids is short to medium-term in pain treatment with the significant danger of addiction and potential overuse leading to death $[20,21]$. Further, adjuvant analgesics including anticonvulsants, anti-depressants, and anxiolytics are increasingly used for chronic musculoskeletal pain [22,
23]. Nonpharmacological approaches include physical modalities, cryotherapy, heat therapy, therapeutic exercises, and acupuncture frequently coupled to medication usage [24-36].

Recently, noninvasive nonpharmacological treatments such as transcutaneous nerve stimulation therapy (TENS), laser, and ultrasound therapy have been added to treatment regimens as standalone or adjunctive therapies [37-47]. TENS acts through inhibition of A $\beta$-fibers activated pain [42, 43], laser therapy actives cellular metabolism, increasing growth factor production and matrix production. Ultrasound therapy mechanically and thermally actives the targeted tissue to modulate pain [37, 41, 46-49].

The Food and Drug Administration (FDA) in March 2020 approved Sustained Acoustic Medicine (SAM, ZetrOZ System LLC, FDA 510(k) \#K191568, Class II, Medical Device) for prescription home use to treat pain, increase local circulation and improve joint function [49]. SAM utilizes high-frequency, low-intensity continuous ultrasound at $3 \mathrm{MHz}$ with $0.132 \mathrm{~mW} / \mathrm{cm}^{2}$ intensity delivering $18,720 \mathrm{~J}$ over $4 \mathrm{~h}$ of the treatment [50-52]. The SAM device allows for the long duration delivery of ultrasound stimulation to facilitate the healing of injured musculoskeletal tissue in the home of the patient $[50,53,54]$. SAM has mechanotransductive and diametric effects at the tissue and molecular level utilizing acoustic forces that have short and longterm effectiveness [51]. The diathermic effects increase blood flow to the target site, reduce local inflammation, increase blood flow, promote vasodilation, eliminate damaged tissue, and enhance exchange of nutrients [55]. The ultrasound mechanotransduction process actives the transmembrane ionic channels and regulate the cellular metabolism [56-58]. The intracellular FAK/ NF-KB/P13K/MAPK pathways are also activated with stimulation leading to cellular proliferation, migration [59-61]. Collectively the long-duration ultrasound treatment provided by SAM pass deep into the tissue, increasing vessel diameter and blood flow at the injury site (Fig. 1C). The acoustic force increases the permeability of capillary epithelial walls and matrix, allowing the release of nutrients and removing cytokines and damaged tissue (Fig. 1B). Long-term application of SAM augments the healing process by increasing cellular proliferation rate (Fig. 1A).

This systematic review and meta-analysis aim to summarize the clinical effects of SAM treatment on musculoskeletal injuries including diathermy (tissue heating), functional outcomes (strength and range of motion), quality of life, pain reduction, and safety profile of the intervention. 


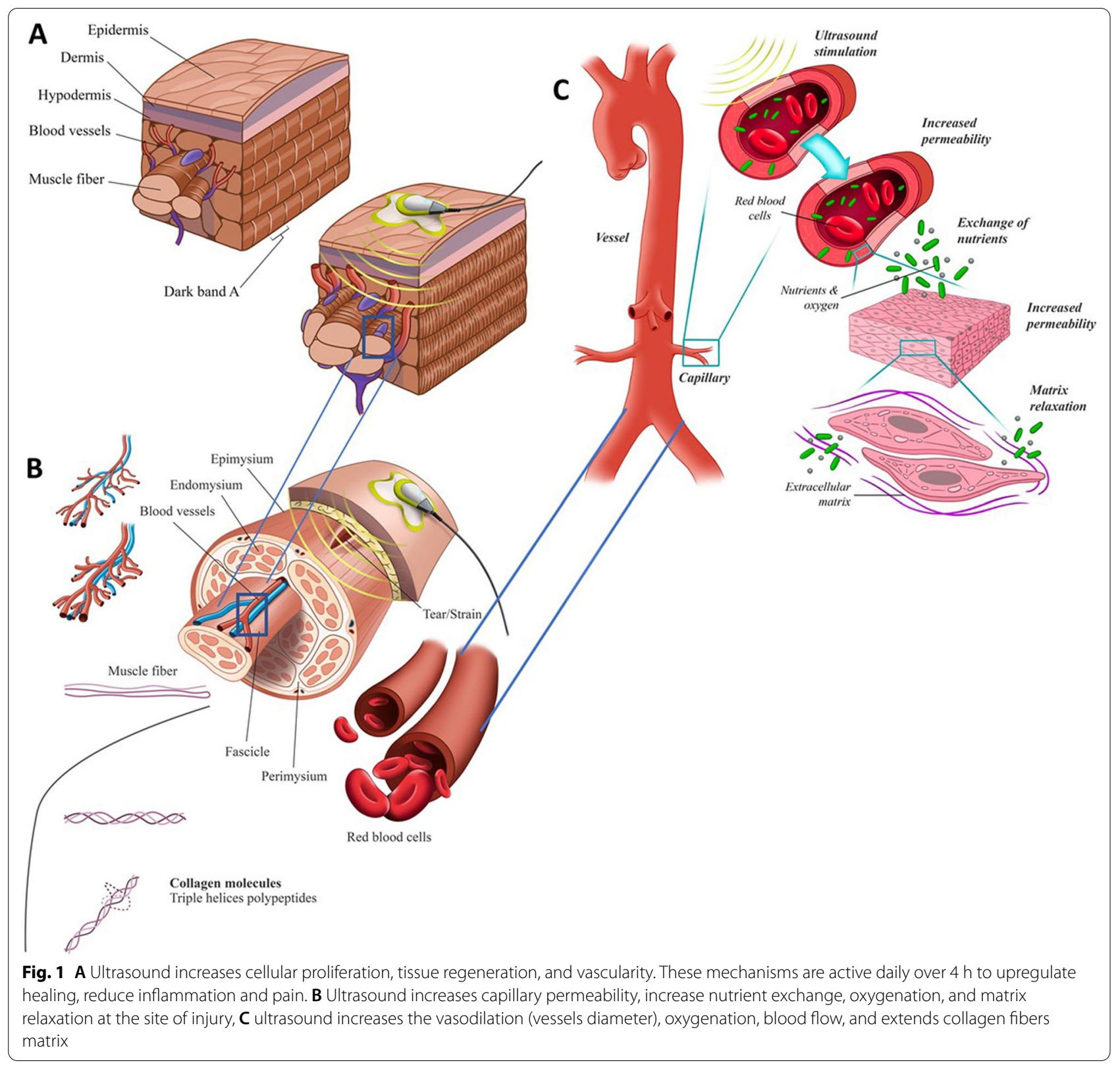

\section{Methods}

\section{Protocol}

This systematic review and meta-analysis were performed and reported in accordance with the guidelines described by The PRISMA 2020 statement [62].

\section{Inclusion criteria}

Studies were included if they applied SAM treatment to human participants (aged 18 and over) with institutional review board approval or exemption; and if they were published in English, original research or peer-reviewed, related to the musculoskeletal treatment (musculoskeletal injuries, musculoskeletal pain, pre or post operative rehabilitation, mechanistic biological stimulation, or human-factor usability); level IV (case cohort) or higher evidence based on Levels of Evidence, Oxford Centre for Evidence-Based Medicine, 2009; used validated outcome measurement methods (musculoskeletal pain, musculoskeletal function, musculoskeletal biological measures, musculoskeletal heating, therapeutic complications and/or adverse events); included study designs of comparative, case cohort or qualitative studies. 


\section{Search strategy}

Relevant literature was searched to identify studies of level IV or higher (Oxford Centre) measuring clinical benefit of the SAM device in clinical research applications up to $09 / 10 / 2021$. Measurable clinical outcomes included: pain, function, tissue-heating (diathermy), strength, recovery, and return to work. The PRISMA flow diagram for identifying relevant research is shown in Fig. 2. PubMed, EBSCOhost, Academic Search Complete, Google Scholar and ClinicalTrials.gov search engines and databases were queried with the search terms used for identifying studies: "Sustained Acoustic Medicine" OR "SAM" ( $\mathrm{n}=62)$, "Low-Intensity Therapeutic Ultrasound" OR "LITUS" $(\mathrm{n}=160)$, "Low-Intensity Continuous Ultrasound" OR "LICUS” ( $\mathrm{n}=120)$, "Wearable Therapeutic Ultrasound" $(n=20)$, "Low-Intensity Wearable Ultrasound" $(n=7)$. The search was limited to 2011-2021, i.e., the last ten years. Combination of search terms with "AND" and "OR", along with a review of references cited within identified studies and related articles was used to uncover all relevant literature on Sustained Acoustic Medicine treatment.

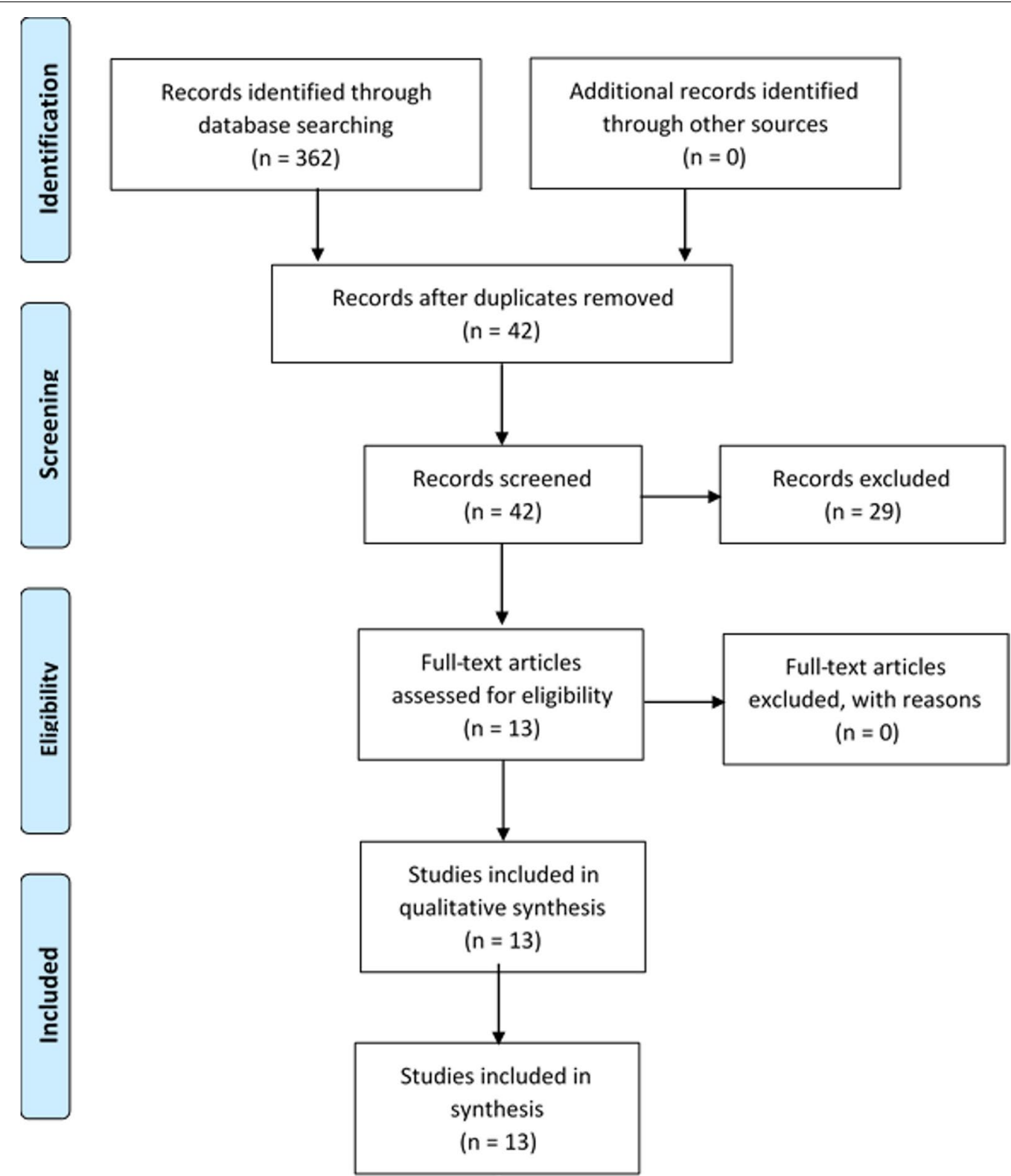

Fig. 2 PRISMA flow diagram for identification, screening, eligibility and included articles in SAM clinical study analysis 


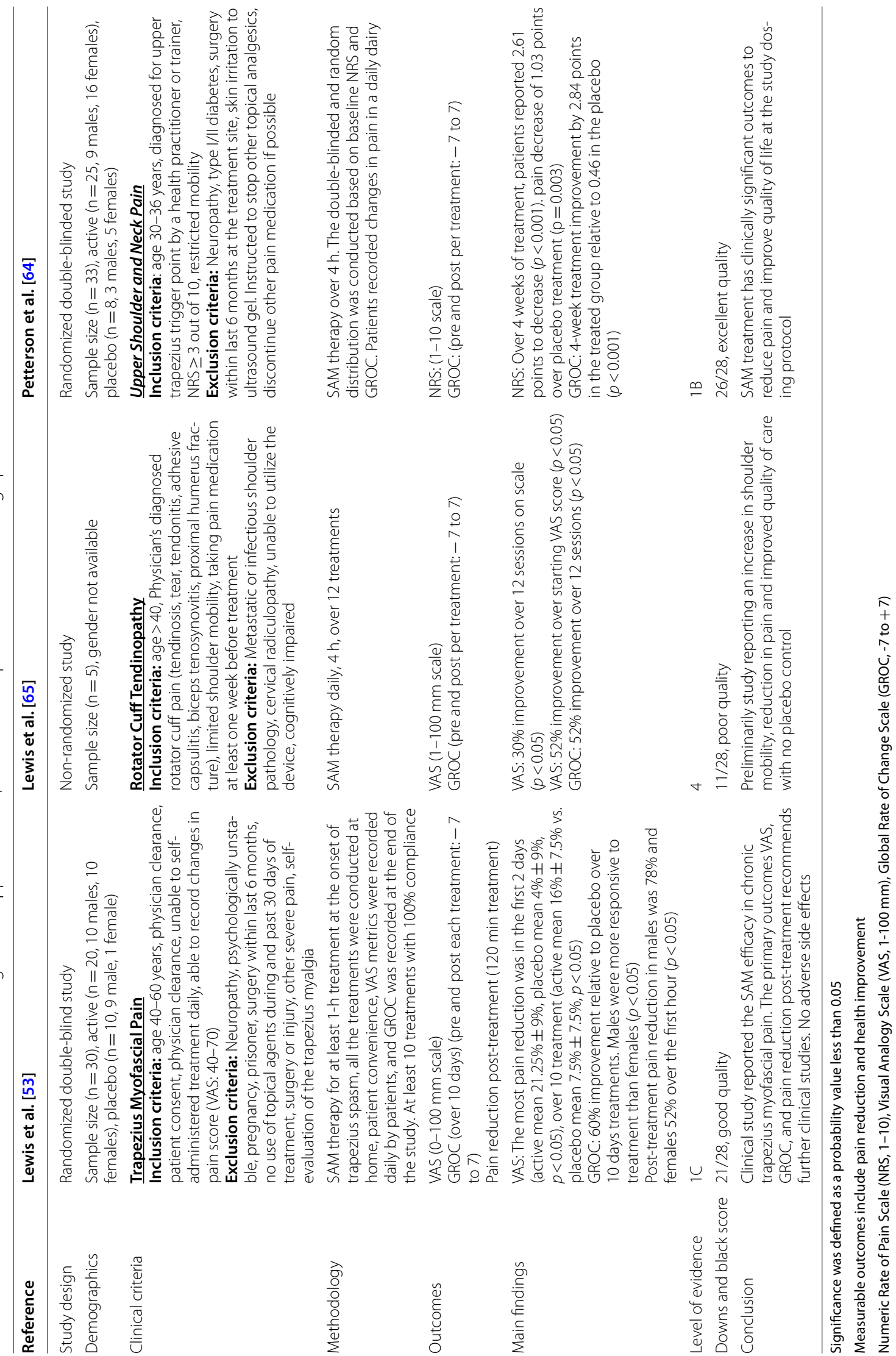




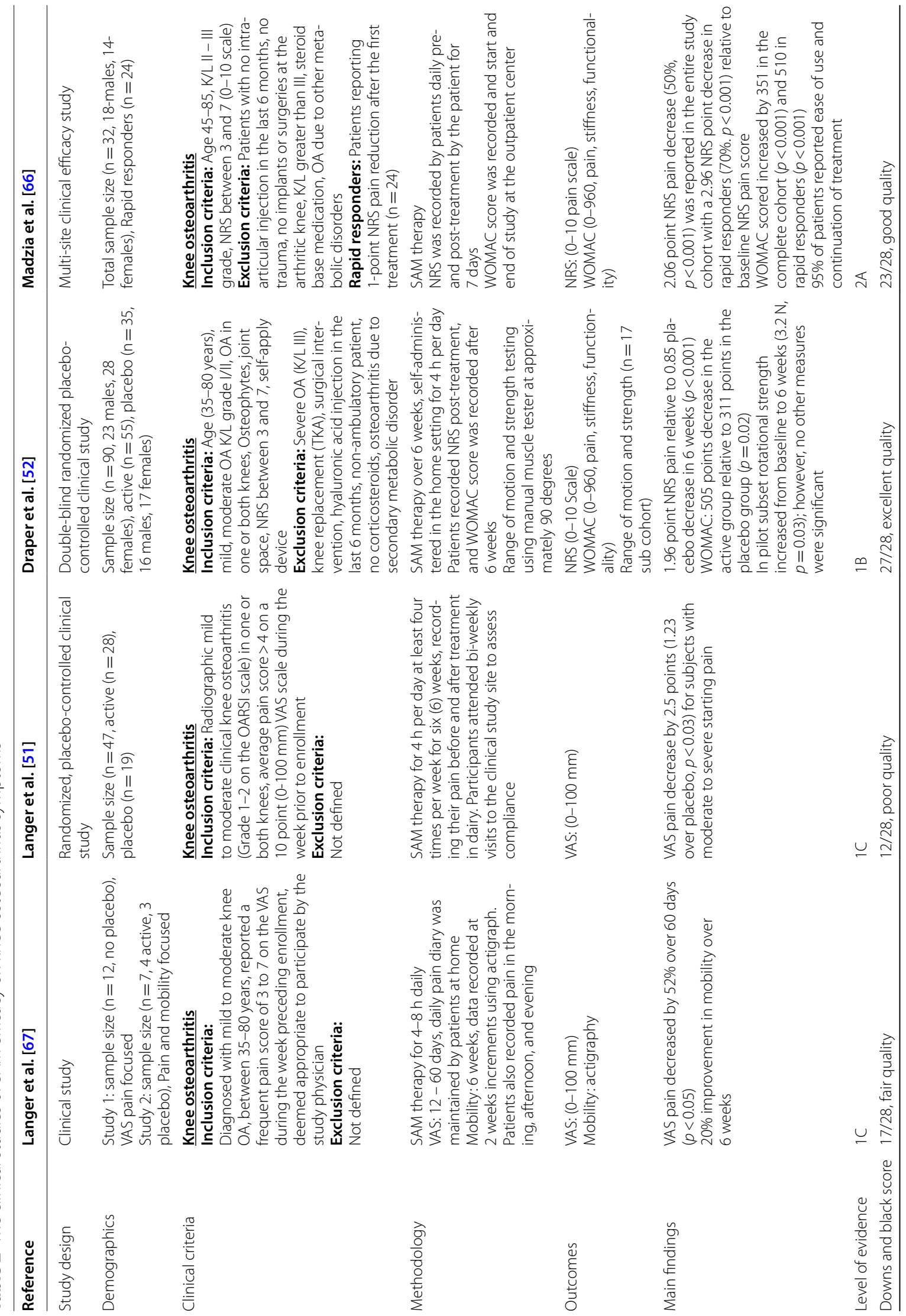




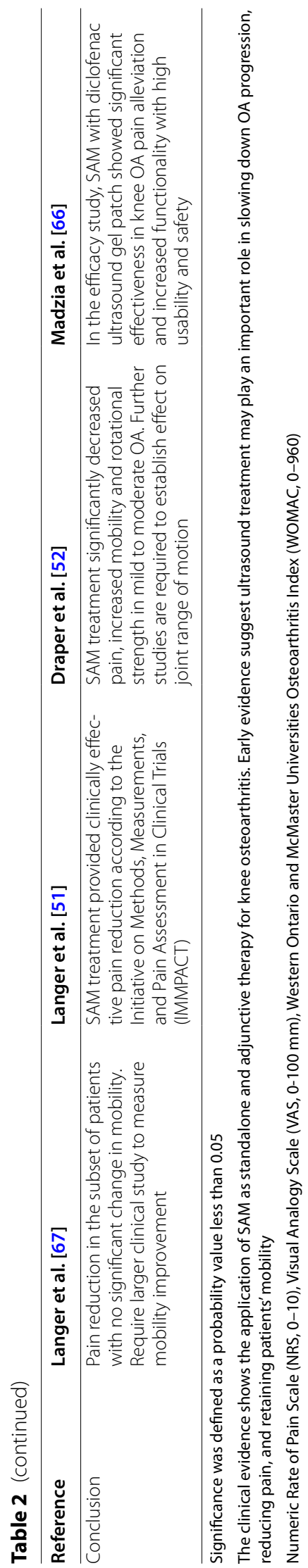




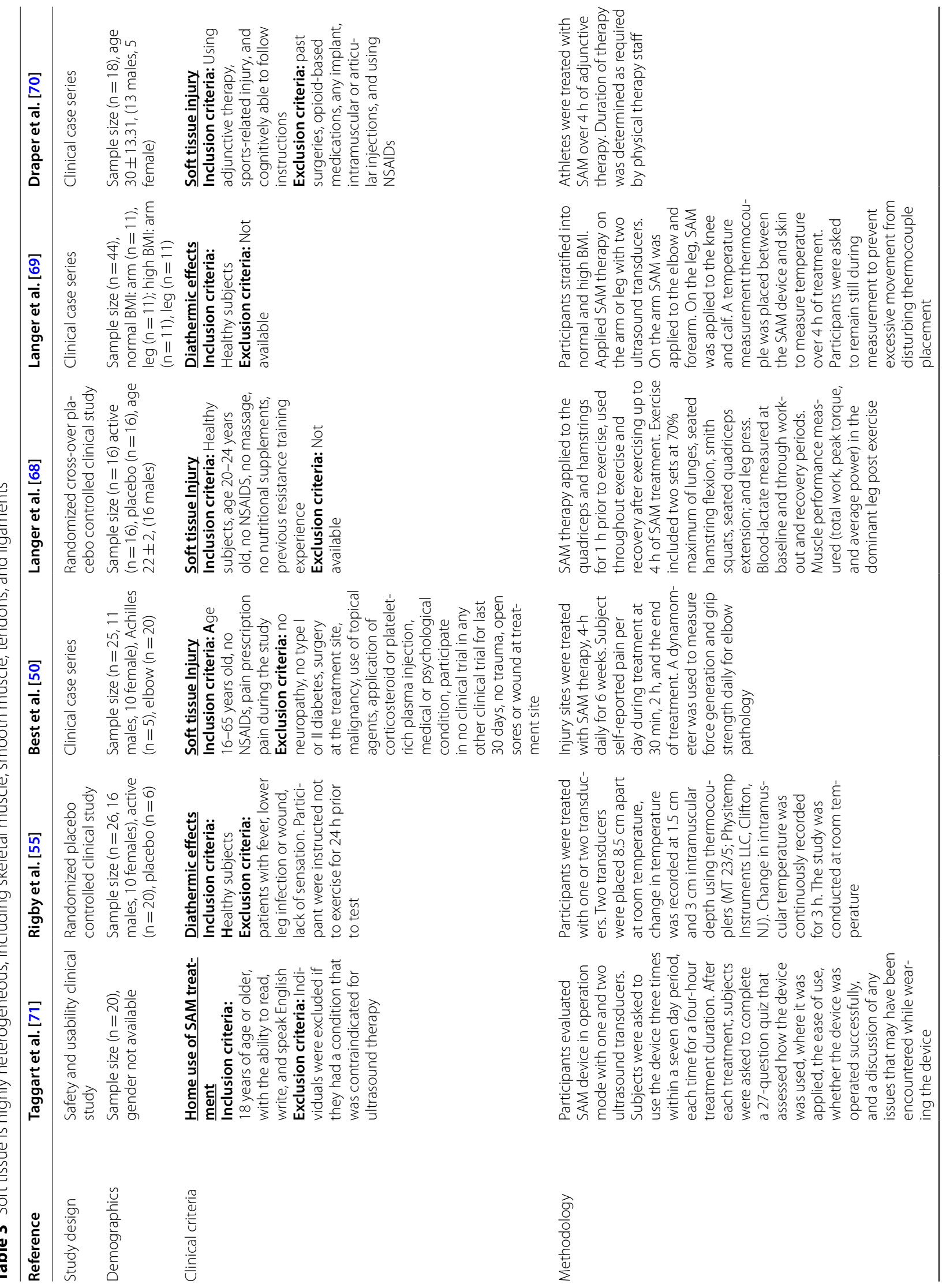




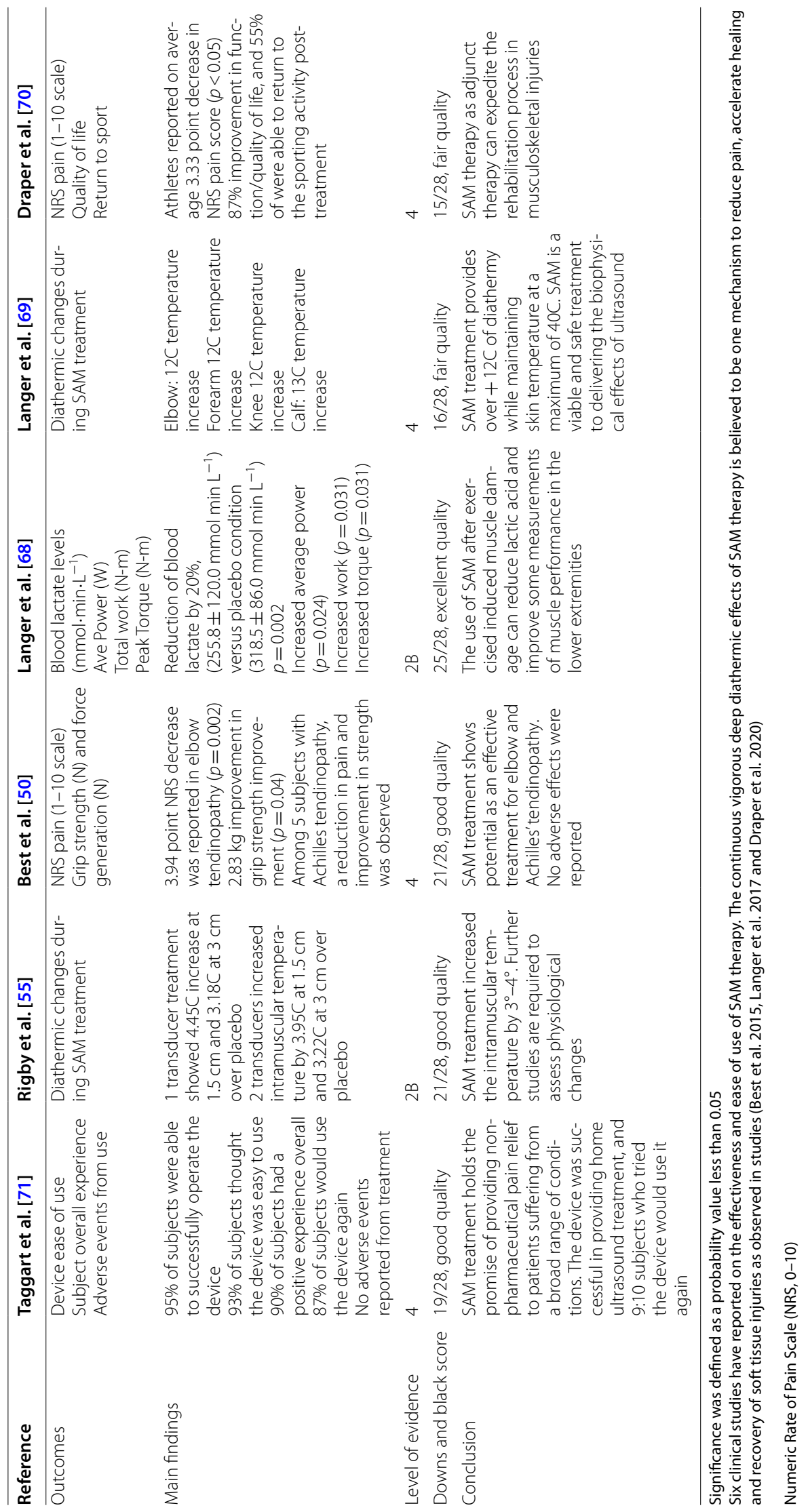




\section{Study selection}

All references were exported, and duplicates removed. Two investigators (SW, TB) screened titles and abstracts as per the inclusion criteria and retrieved full text for further analysis. Disagreements were resolved by a third reviewer (AU).

\section{Data collection process}

The two investigators (SW and TB) independently extracted data from the selected studies and complied them into tables. The data collected included study characteristics (authors, date of publication, study design and clinical registration), study musculoskeletal focus area (body location, injury type, condition treated), and variables associated with measurable outcomes (pain, function, quality of life, diathermy, return-to-work, adverse events, safety profile and participant satisfaction). Extractable variables were pooled and stratified to similar conditions on reported outcomes in the literature for synthesis.

\section{Risk of bias and quality of evidence assessment}

A total of 362 records were identified and a total of $n=13$ clinical studies including five (5) level I, four (4) level II and four (4) level IV studies were selected for assessment. The quality of each selected study was scored by two investigators (SW and $\mathrm{TB}$ ) using the Downs and Black checklist [63] and investigator (AU) was consulted in the cases of discrepancy. The Downs and Black 27 question check list has a maximum score of 28 points and provides detailed quality evaluation of randomized controlled and non-controlled studies for external validity, internal validity, and power. Downs and Black quality scores were tabulated for all studies based on the following tiers (poor quality $<14$, fair quality $14-18$, good quality $19-23$ and excellent quality $>23$ ).

\section{Synthesis of results}

Two authors (SW and TB) completed the analysis using both Microsoft Excel (Microsoft, USA) and Review Manager Version 5.4 (The Cochrane Collaboration, Denmark). A fixed effects meta-analysis with standardized mean difference (SMD) statistics was used to analyze the results where two or more controlled studies could be analyzed. The $\mathrm{I}^{2}$ statistic was used to assess study heterogeneity within the meta-analysis. Analysis was conducted on studies grouped by body location and condition being treated, and according to outcomes measure (pain, health improvement and tissue heating). Given the limited evidence uncovered (13 studies) and variability in design amongst the studies (joint, tendon and soft tissue pain; function elbow, knee, and ankle; soft-tissue health improvement, deep heating of muscle tissues, biological measures of lactic acid), data groupings were made according to time points analyzed and reported and standardized for comparison controls where available. In cases where it was not possible to undertake meta-analysis such as limited evidence for a specified comparison (lack of a control group) and/or only one study available on an outcome, data was extracted into tables and main findings reported.

\section{Results \\ Study selection}

The PRISMA flow diagram is shown in Fig. 2. The search strategy yielded a total of 362 citations from the four search engines and clinical trial databases. No additional included studies were retrieved from other sources including references lists, related articles, manual searching or Cochrane library and EMBASE databases. After removing the 320 duplicates uncovered, 42 citations were screened by reading the study abstract. The remaining 13 relevant records were then analyzed for eligibility based on full text availability and inclusion criteria. The thirteen (13) clinical studies meeting inclusion criteria were divided as follows: upper shoulder, neck and back (Table 1), knee joint (Table 2), and soft tissue injuries of the musculoskeletal system (Table 3).

\section{Upper neck, back and shoulder conditions Study characteristics and participants}

The study characteristics and participants for upper neck, back and shoulder conditions are reported in Table 1 . The three eligible studies comprised two randomized controlled trials (RCTs) [53, 64] and one prospective non-randomized study [65]. Two of the three studies compared an intervention group (SAM) with a placebo control group (Non-Functioning Device) in the treatment of upper back myofascial pain and upper shoulder and neck pain, and one study evaluate SAM in a case cohort on rotator cuff tendinopathy. Among the included studies, two were single center conducted in the United States [53, 65]. One was a multicenter trial conducted in the United States [64]. The included studies involved a total of 67 participants who received SAM treatment in additional to usual care for musculoskeletal injury or pain. One study included patients 40-60 years of age with chronic trapezius myofascial pain [53], one study included younger 30-36 years of age patients with episodic upper shoulder and neck pain [64], and another study on shoulder tendinopathy included patients over 40 years of age [65]. Both men and women were equally represented in the include studies (31 males, 32 females, 5 unreported). 


\section{Study intervention characteristics}

The characteristics and methodology of SAM treatment for upper neck back and shoulder conditions are reported in Table 1. Two studies applied SAM treatment with one ultrasound delivery head operating at $2.5-3 \mathrm{MHz}, 0.44-$ $0.65 \mathrm{~W}$ and $89.6-90 \mathrm{~mW} / \mathrm{cm}^{2}$ for $1-4 \mathrm{~h}$, respectively $[53,65]$. One study applied two SAM ultrasound delivery heads operating at $3 \mathrm{MHz}, 1.3 \mathrm{~W}(0.65 \mathrm{~W}$ each), 132 $\mathrm{mW} / \mathrm{cm}^{2}$ for $4 \mathrm{~h} \mathrm{[64]}$. SAM treatment was applied during heightened or breakthrough pain in two studies [53, 64], and on a daily treatment regimen for shoulder injury in the other study [65]. All three studies used SAM for at least 10 treatment sessions over a course of two weeks, and one study applied the intervention for 4 weeks [64].

\section{Level of evidence and quality of studies}

The level of evidence and quality assessment of the studies is shown in Table 1. One study was considered poor quality [65], one study of good quality [53] and one study of excellent quality [64]. Two RCTs blinded evaluators and subjects, and clearly reported objectives, described the outcomes to be measured and the main findings [53, 64].

\section{Study outcomes and main findings}

The primary outcomes and main findings from the included studies are shown in Table 1. Pain reduction using the visual analog scale (VAS 1-100 $\mathrm{mm}$ ) or numeric rating scale (NRS 0-10), and overall health improvement using the global rate of change scale (GROC: -7 to +7 ) were evaluated in all included studies and supported meta-analysis. Lewis et al. [53] in a 30 subject RCT on myofascial pain reported a $200 \%$ reduction in pain $(16 \%$ vs. $7.5 \% p<0.05)$ compared to placebo, and a $60 \%$ GROC improvement over the placebo group after 10 SAM treatment sessions $(p<0.05)$. In the pilot study by Lewis et al. [65] 5 patients with rotator cuff tendinopathy reported a $30 \%$ reduction in pain and a $52 \%$ improvement in the GROC after 12 SAM treatment session $(p<0.05)$. In a 33 subject RCT on upper neck and shoulder pain conducted by Petterson et al. [64] pain was reduced by 2.61 points (46.6\%) for SAM treatment patients $(p<0.001)$ and a 1.03 points decrease over placebo $(p=0.003)$ after 4 weeks of intervention. Petterson et al. [64] also reported a 2.84 point GROC improvement over placebo treatment $(p<0.001)$.

The meta-analysis and forest plot of SAM treatment outcomes on pain and global health improvement compared to placebo treatment are shown in Fig. 3 for upper back, neck, and shoulder conditions. The availability of two randomized controlled trials provided a Pain Reduction (SMD 0.82; 95\% CI 0.25-1.40; $\mathrm{I}^{2}=0 \%$; $\mathrm{n}=63$ ) and Global Health Improvement (SMD 1.40; 95\% CI $0.79-2.02 ; \mathrm{I}^{2}=25 \% ; \mathrm{n}=63$ ). There were significant between-group differences found in pain $(p=0.005)$ and health improvement $(p<0.0001)$ with low heterogeneity between studies ( $\mathrm{I}^{2}$ values $\left.\leq 25 \%\right)$. The two studies in these outcomes were graded as good to excellent $[53,64]$.

\section{The knee joint Study characteristics and participants}

The study characteristics and participants for knee joint conditions treated by SAM are reported in Table 2. The four eligible studies comprised two randomized controlled trials (RCTs) [51, 52] one prospective multi-site non-randomized study [66] and two combined pilot studies [67]. Three of the four studies compared an intervention group (SAM) with a placebo control group (Non-Functioning Device) in the treatment of mild to moderate grade knee Osteoarthritis on clinically validated scales (Kellgren and Lawrence system for classification of osteoarthritis or Osteoarthritis Research Society International Scale). Among the included studies, three were single center [51, $52,67]$ and one was a multicenter trial [66] all conducted in the United States. The included studies involved a total of 156 subjects who received SAM treatment in additional to usual care for knee joint pain. All studies included patients 35-85 years of age with chronic knee Osteoarthritis pain and radiographic diagnosis. Men represented 57\% and women $43 \%$ of the described study populations across the four studies (41 males, 31 females, 66 unreported).

\section{Study intervention characteristics}

The characteristics and methodology of SAM treatment for knee joint pain related to Osteoarthritis is shown in Table 2. All four studies applied SAM treatment at $3 \mathrm{MHz}, 132 \mathrm{~mW} / \mathrm{cm}^{2}$ for 4 h daily [51, 52, 66, 67]. One study applied one SAM ultrasound delivery head operating delivering $0.65 \mathrm{~W}$ of energy [67], the other three studies applied SAM treatment with two ultrasound delivery heads operating at $1.3 \mathrm{~W}$ over for $4 \mathrm{~h}[51,52,66]$. One study utilized a $1 \%$ diclofenac ultrasound coupling gel with the intervention [66]. SAM treatment was applied to the knee daily with patients reporting baseline pain scores from 3 to 7 on the 10-point scale. Three studies applied SAM for at least 6 weeks of treatment $[51,52,67]$ and one study applied SAM for one week of treatment [66].

\section{Level of evidence and quality of studies}

The level of evidence and quality assessment of the studies is shown in Table 2. One study was poor quality [51], one study was fair quality [67], one study was good quality [66] and one study of excellent quality [52]. Two RCTs 


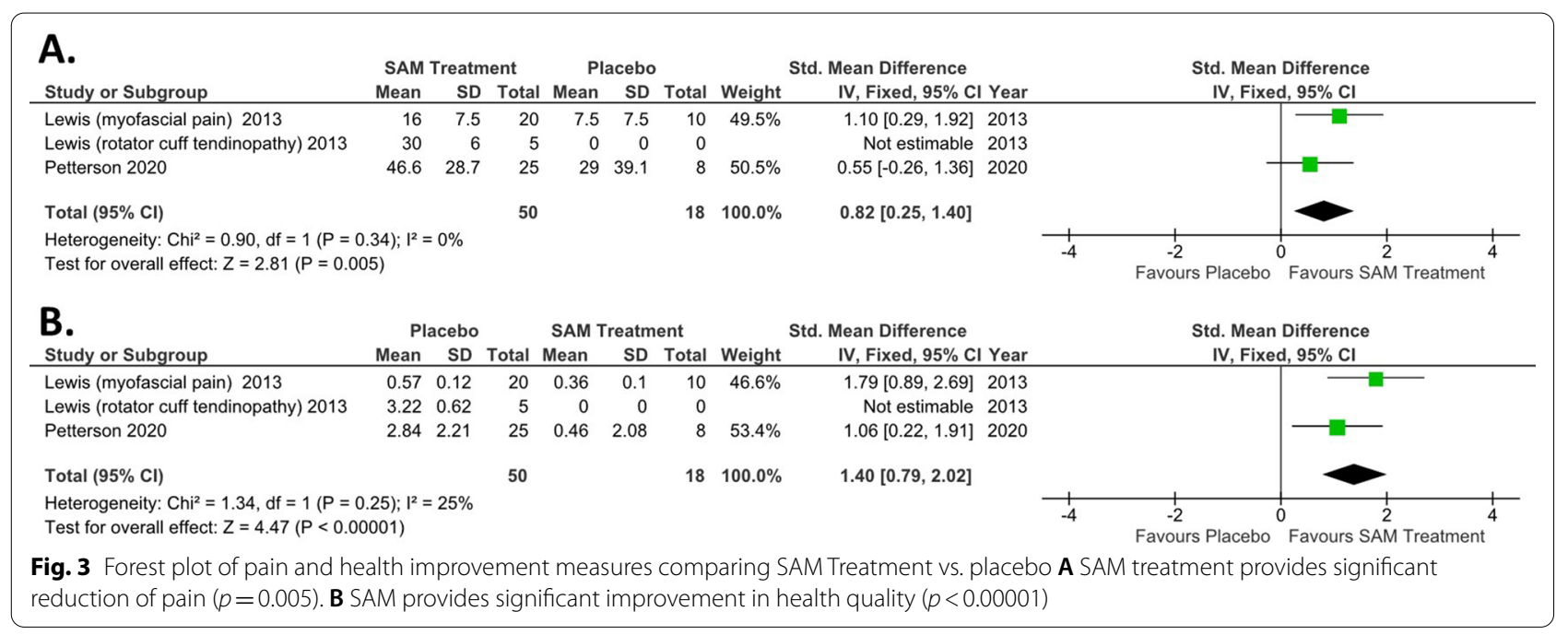

blinded evaluators and subjects, and clearly reported objectives, described the outcomes to be measured and the main findings $[51,52]$. Two studies lacked detail and were preliminary pilot studies or short reports on registered studies [51, 67].

\section{Study outcomes and main findings}

The primary outcomes and main findings from the included knee joint studies are shown in Table 2. Pain reduction using the visual analog scale (VAS 1-100 mm) or numeric rating scale (NRS 0-10) was used in all four studies. Knee joint functional improvement using The Western Ontario and McMaster Universities Arthritis Index (WOMAC: 0-960 scale including 24 questions related to pain, stiffness, and function) score was applied across two studies [52, 66], and range of joint motion was evaluated in one study [52]. The study conducted by Langer et al. 2014 showed the initial usability of SAM treatment for knee OA [67]. Patients, on average, reported a $52 \%$ reduction in the pain score from baseline with no adverse effects and 95\% satisfaction of treatment $(\mathrm{p}<0.05)$. Langer et al. 2015 in a clinical review on SAM, reported results of a 47 subject randomized placebo-controlled study evaluating treatment on Knee Osteoarthritis [51]. Over 6 weeks, SAM reduced pain on the VAS by 2.5 points which was statistically different from the 1.23-point decrease of the placebo group $(p<0.03)$. A 90 -subject double-blinded, placebo-controlled study by Draper et al. 2018 reported a 1.96-point decrease in NRS pain relative to placebo treatment $(p<0.01)$ [52]. WOMAC function, stiffness and pain score improved by 505 points for the SAM treatment group $(p<0.01)$. In a 32 patient multicenter study on knee Osteoarthritis, Madzia et al. [66] reported 2.06 -point $50 \%$ pain decrease in the entire cohort $(p<0.001)$ and 2.96 -point $75 \%$ pain decrease in responders $(p<0.001)$. The WOMAC score improved by 351 points in the entire population $(p<0.001)$ and 510 points $(p<0.001)$ in the rapid responder cohort. A high usability rate over 95\% patient satisfaction and no adverse events were also reported.

The meta-analysis and forest plot of SAM treatment outcomes on pain reduction compared to placebo treatment are shown in Fig. 4 for the knee joint. The availability of two randomized controlled trials and one controlled pilot study provided a Pain Reduction (SMD

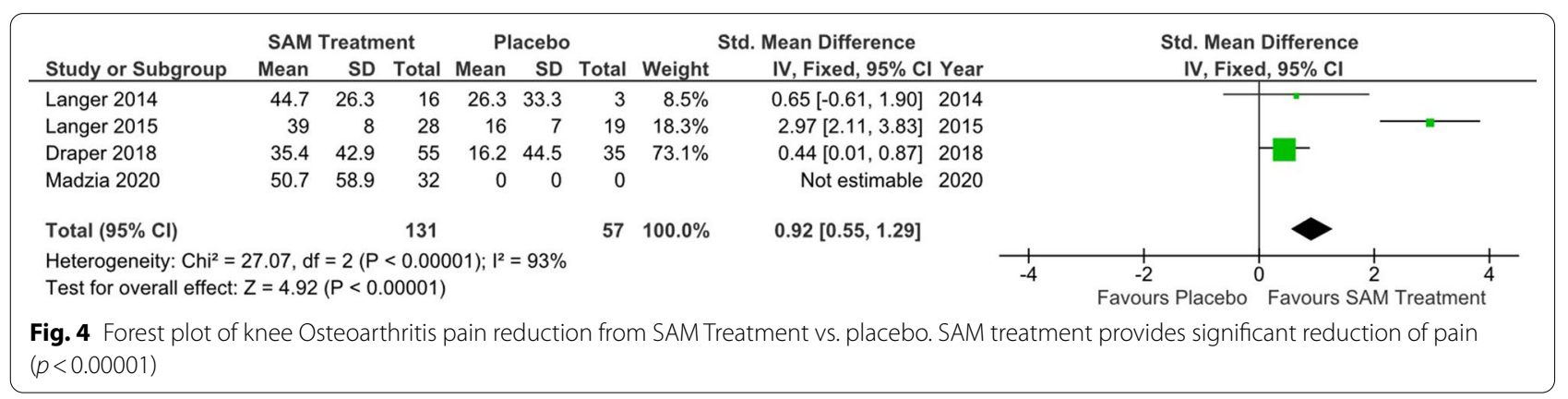


0.92; 95\% CI 0.55-1.29; $\mathrm{I}^{2}=93 \% ; \mathrm{n}=63$ ). There were significant between-group differences found in pain $(p<0.00001)$. The included studies had high heterogeneity $\left(\mathrm{I}^{2}\right.$ values $\left.\geq 50 \%\right)$ which was not meaningfully reduced by exclusion of a data set. The three studies included in these outcomes were graded as poor to excellent quality. Other measures such as WOMAC were not sufficiently available to conduct analysis on.

\section{Patient-self treatment and soft tissue injuries Study characteristics and participants}

The study characteristics and participants for patientself-treatment and soft tissue injuries treated by SAM are reported in Table 3 . The six eligible studies comprised two randomized controlled trials (RCTs) [55, 68], three clinical case series $[50,69,70]$ and one safety and usability study [71]. Two of the six studies compared an intervention group (SAM) with a placebo control group (Non-Functioning Device) in proving deep heat (ultrasonic diathermy) to muscle tissue and increasing muscle performance and recovery after high impact exercise [55, 68]. All six studies were single center trials conducted in the United States. The included studies involved a total of 149 subjects who received SAM treatment in a variety of musculoskeletal injuries and/or were conducted to measure SAM therapeutic performance and mechanisms of action in human subjects. Two studies were conducted on deep tissue heating on various locations of the body $[55,69]$, one study on quad and hamstring muscle performance and biomolecular measures [68], one humanfactor usability and safety study applying SAM to various physical locations on the body [71], and two clinical studies focused on healing soft-tissue injuries to musculoskeletal tissue [55, 70]. Studies included both injured and healthy subjects 18 years of age or older, men represented $69 \%$ and women $31 \%$ of the described study populations across the four studies (56 males, 25 females, 64 unreported).

\section{Study intervention characteristics}

The characteristics and methodology of SAM treatment for patient self-treatment and soft tissue injuries is shown in Table 3. All six studies applied SAM treatment at $3 \mathrm{MHz}, 132 \mathrm{~mW} / \mathrm{cm}^{2}$ for $4 \mathrm{~h}$ daily $[50,55,68-71]$. Two studies varied SAM treatment between one and two ultrasound delivery heads operating delivering $0.65 \mathrm{~W}$ or $1.3 \mathrm{~W}$ to determine usability and safety [71] and deep heating (diathermy performance) [55]. The other four studies applied SAM treatment with two ultrasound delivery heads operating at $1.3 \mathrm{~W}$ over for $4 \mathrm{~h}$ [55, 68$70]$. One study utilized four SAM devices on each subject during regular therapy sessions delivering 5.2 W [68]. Across all six studies SAM treatment was applied directly over the injury site or over the specified target region looking to be evaluated.

\section{Level of evidence and quality of studies}

The level of evidence and quality assessment of the studies is shown in Table 3. Two studies were fair quality $[69,70]$, three studies were good quality $[50,55,71]$ and one study of excellent quality [68]. Two RCTs blinded subjects, and clearly reported objectives, described the outcomes to be measured and the main findings [55, $68]$. One prospective case series attempted to blind subjects of the treatment [50]. The remaining three studies included sufficient detail but did not have specific controls due to the study design and/or purpose [69-71].

\section{Study outcomes and main findings}

The primary outcomes and main findings from the included studies on self-treatment and soft tissue injury are shown in Table 3. Soft tissue injury pain reduction using numeric rating scale (NRS 0-10) was used in two studies [50, 70]. Measures of functional improvement such as range of motion, dynamometer, strength, and power were applied in three studies [50, 69, 70]. Two study measured diathermy temporal heating profiles with thermocouples in situ $[55,69]$. One study included blood measures of lactic acid clearance [68]. One study included usability and satisfaction of treatment [71].

A placebo-controlled study by Rigby et al. $2015(n=26$ subjects, 20 active, 6 placebo) measured the diathermic effects of one and two SAM transducer setups at $1.5 \mathrm{~cm}$ and $3 \mathrm{~cm}$ intramuscular depth over $3 \mathrm{~h}$ [55]. The $3-4{ }^{\circ} \mathrm{C}$ temperature increase occurred over $3 \mathrm{~h}$, leading to increased blood flow, vasodilation, and oxygenation of the intramuscular tissue. Langer et al. 2017 ( $n=44$ subjects, 22 normal body mass index (BMI) and 22 high BMI) evaluated two SAM transducers for diathermy on the elbow, forearm, knee, and calf [69]. Langer et al. 2017 compared clinical experimental data to mathematical modeling of the diathermy generated by SAM [69]. Over the 4-h SAM treatment and temperature recording, the temperature directly below the SAM ultrasound transducer increased from 12 to $13{ }^{\circ} \mathrm{C}$ in approximately $20 \mathrm{~min}$ of use and sustained for the duration of treatment. The prediction model of diathermy was able to predict the clinical measurements closely. A human-factor clinical usability study by Taggart et al. 2014 ( $n=20$ subjects) evaluated the effective application of SAM treatment in the home and clinic setting [71]. Over 60 unique SAM treatment sessions, $95 \%$ of subjects successfully applied and operated the device, and $93 \%$ found the treatment easy to use.

Best et al. 2015 reported the efficacy of SAM therapy in controlled case studies including Achilles and elbow 
tendinopathy ( $\mathrm{n}=25$ subjects) [50]. Patients were treated for $4 \mathrm{~h}$. daily over 6 weeks. Patients reported change in pain at $30 \mathrm{~min}, 2 \mathrm{~h}$, and the end of each treatment $(4 \mathrm{~h})$. Dynamometer force and grip strength measurements were taken pre and post. Patients reported a 3.94 point on average reduction in pain over 6 weeks on NRS pain scale $(p=0.002)$ and a $2.38 \mathrm{~kg}$ improvement in grip strength $(p=0.04)$. An overall reduction in pain was observed within the $4-\mathrm{h}$ treatment sessions $(p<0.001)$ as well.

A randomized placebo-controlled cross-over study design by Langer et al. 2017 reported on the efficacy of SAM treatment to improve healing and recovery after muscle injury from high-intensity resistant exercise ( $\mathrm{n}=16$ subjects) [68]. Subjects completed a series of five lower-body resistance exercises with active and placebo SAM treatment applied to the quadriceps and hamstrings at rest and during the exercise bouts. Blood lactate concentration was measured along with isokinetic dynamometer measurements during leg extension and flexion exercises. At each post-exercise time point measured, the lactate concentration was reduced in the active treatment $255.8 \pm 120.0 \mathrm{mmol} \mathrm{min} \mathrm{L}^{-1}$ compared to the sham treatment $318.5 \pm 86.0 \mathrm{mmol} \mathrm{min} \mathrm{L}^{-1}(p=0.002)$, reflecting a $20 \%$ average decrease in total blood lactate levels after $1 \mathrm{~h}$ of recovery with SAM. There were also improvements in muscle performance with active versus placebo SAM treatment, including increased peak torque at $90^{\circ} \mathrm{sec}^{-1}$ into extension $(p=0.031)$, increased total work at $90^{\circ} \mathrm{sec}^{-1}$ into extension $(p=0.027)$ and average power output at $90^{\circ} \mathrm{sec}^{-1}$ into extension $(p=0.024)$. Similarly, Draper et al. 2020 conducted a set of case studies $(\mathrm{n}=18)$ using SAM as an adjunct therapy in athletic injuries from sports [70]. The therapy was applied at various anatomic sites targeting multiple soft tissues such as ligament, muscle, and tendon. The study reported NRS, quality of life, and return of return to sports as outcome measures. There was a 3.33-point decrease in NRS pain score $(p<0.05), 87 \%$ improvement in quality of life, and $55 \%$ of the athletes successfully returned to active sports.

The meta-analysis and forest plot of SAM treatment outcomes on diathermy compared to placebo/ no-treatment are shown in Fig. 5 . The availability of one randomized controlled trial and one case series with baseline measure provided demonstrated increased heating (SMD 5.49; 95\% CI 4.59-6.39; $\mathrm{I}^{2}=97 \% ; \mathrm{n}=114$ ). There were significant between-group differences found in tissue heating $(p<0.00001)$. The included studies had high heterogeneity $\left(\mathrm{I}^{2}\right.$ values $\left.\geq 50 \%\right)$ related to location (internal vs. external) diathermy measurement on the body. The two studies included in this outcome were graded as fair to good quality. Other measures such as pain, lactic acid, and functional measures were not sufficiently available to conduct meta-analysis on.

\section{Discussion}

Musculoskeletal pain and soft-tissue injuries are highly prevalent with a significant impact on quality of life and the economy [5]. Acute pain is treatable with standard short-term use of NSAIDs, but chronic pain can significantly impair daily life. The transition from acute to chronic pain has been an unmet challenge in clinical sciences [14]. Pain management has been an ongoing research topic, but there is a need for therapies that are not limited to pain management and expedite the healing process by activating underlying physiological processes at the tissue, cellular, and molecular level. Current strategies employing NSAIDs, and opioid-based drugs have well known healing limitations and risks [2, 46, 72]. The overuse of NSAIDs has a significant adverse effect on gastric organs, kidneys, and liver, while overuse of opioid-based drugs has led to the opioid pandemic [2]. Neither of these therapies has regenerative effects; they ultimately lead to invasive procedures such as total hip arthroplasty, total knee arthroplasty, rotator cuff surgeries, etc. $[73,74]$.

As a recently approved FDA home-use treatment in 2020 [49], this systematic review and meta-analysis aimed to investigate and summarize the effects of Sustained Acoustic Medicine (SAM) therapy in musculoskeletal applications for the healthcare community. The clinical literature on SAM demonstrates it as a clinically effective mechanobiological that applies low-intensity continuous high-frequency ultrasound at $3 \mathrm{MHz}, 132 \mathrm{~mW} /$ $\mathrm{cm}^{2}$ and delivers $18,720 \mathrm{~J}$ of energy over $4 \mathrm{~h}$ of treatment $[50,55,65,75]$. It is a prescribed, in-home treatment,

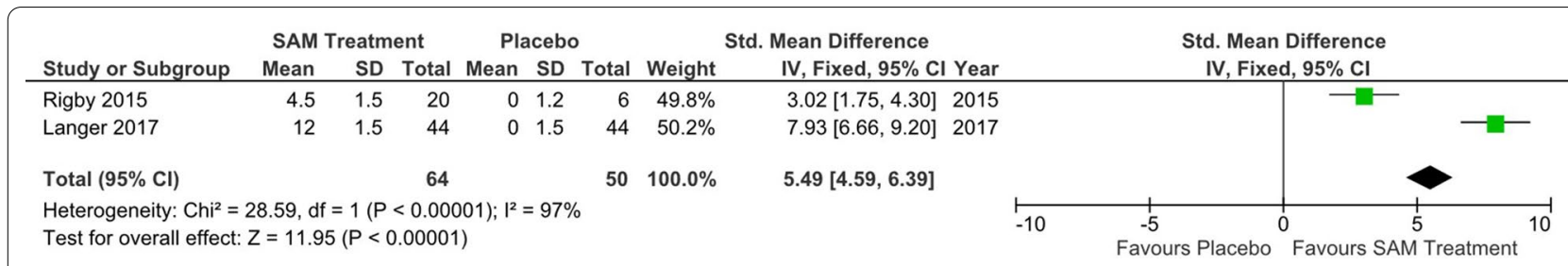

Fig. 5 Forest plot of ultrasound diathermy tissue heating with SAM Treatment vs. placebo. SAM treatment provides significant temperature increase of soft-tissue $(p<0.00001)$ 
that requires little or no supervision from medical staff. Long-duration treatment with SAM shows little or no adverse effects [75]. The treatment is unique as it applies both mechanical and thermal stimuli to activate various cellular and molecular pathways for active pain management and regeneration of damaged tissue. SAM inhibits inflammation, slows down the degeneration, promotes migration of cells, and induces regeneration of new tissue. Collectively, SAM therapy helps in pain management and regenerate mechanically and physiologically functional tissue. SAM is a candidate treatment to manage soft tissue pain and amplify the healing of soft tissue injuries $[64,65]$.

The studies conducted by Lewis et al. 2013 and Petterson et al. 2020 show SAM's ability to manage pain in fibrous and skeletal tissue in the upper shoulder and neck, alleviate pain, and increase shoulder mobility [53, 64]. In addition, studies conducted by Langer et al. 2014, 2015 and Draper et al. 2018 show the efficacy of SAM as a standalone therapy in mild to moderate knee OA [51, 52, 67]. Meta-analysis of the primary outcomes for the pooled studies favored SAM treatment over control, and provides evidence of effective use of SAM and the convenience of home use.

Case series by Best et al. 2015 and Draper et al. 2020 reported the effects of SAM treatment on fibrous and skeletal tissue $[50,70]$. The studies showed strong data in reducing pain, improving grip strength, and returning patients back to work. Usability and diathermic clinical studies by Taggart et al. 2014, Rigby et al. 2015 and Langer et al. 2017 demonstrated SAM as a safe and effective home-use treatment, and a treatment that provided vigorous heating to muscle tissue and various areas of the body [55, 69]. Finally, Madzia et al. 2020 showed the application of SAM as a combination therapy with diclofenac and its ability to rapidly reduce chronic joint pain by $70 \%$ or $440 \%$ greater than placebo [66].

Across the thirteen studies ( $\mathrm{n}=372$ subjects) measurable outcomes on device usability, safety profile, diathermy, pain relief, health improvement, and functional assessment using dynamometry, range of motion and grip strength were measured. Table 4 presents the SAM systematic reviews pooled findings with nine $(n=9$ studies demonstrating musculoskeletal pain relief), six $(\mathrm{n}=6$ studies demonstrating functional joint improvement), three $(\mathrm{n}=3$ studies demonstrating improved quality of health), three ( $\mathrm{n}=3$ studies showing a mechanism of SAM biological action in situ), thirteen $(n=13$ studies reporting no adverse events and excellent safety profile) and seven ( $\mathrm{n}=7$ studies reporting high compliance and patient satisfaction). Both pain reduction and improved joint function have the strongest evidence for SAM in the literature with $(n=9)$ and $(n=6)$ studies, respectively reporting significant and clinically meaningful improvements. This was followed by improved quality of life and therapeutic heating reported by $(\mathrm{n}=3)$ and $(\mathrm{n}=2)$ studies, respectively. In sub categorical meta-analysis by body location and condition type, both pain reduction and global health score quality improvement significantly favored SAM treatment. Of the thirteen $(n=13)$ studies reported herein, 7 of 13 were registered on the national clinical trials database (Table 4). Cumulatively, these studies demonstrate the efficacy of SAM therapy as standalone or adjunctive therapy for the upper back, neck, shoulder, knee, and soft tissue pain reduction along with improved patient mobility, functionality, and return to regular day-to-day life after an injury. The data presented in these clinical studies show positive and significant benefit for patients. Furthermore, recent health economic and SAM practitioner survey analysis support medical guideline adoption for SAM as a novel mechanobiological treatment for patient care $[77,78]$. SAM treatment which is widely used in sports medicine, may be considered more broadly as a noninvasive, safe, and effective treatment option for patients with musculoskeletal pain and soft-tissue injuries [78].

\section{Future perspective}

SAM has shown excellent results in rehabilitation and pain management, but there are various other potential applications for low-intensity continuous ultrasound (Fig. 6A). This modality has been shown to have chondroprotective effects and slow down the progression of arthritis in clinical studies (Fig. 6B) [79]. More studies are required to understand the underlying mechanism, but it is known that ultrasound inhibits detrimental inflammatory effects on articular cartilage [40, 80, 81]. The FDA has approved low-intensity pulsed ultrasound for non-union fracture healing, and low-intensity continuous ultrasound has a potential to be used in fracture healing as well $[82,83]$. The acoustic forces and mechanical stimuli generated by SAM over a longer time course could play a pivotal role in accelerating endochondral ossification, differentiation of chondrocytes based on soft callus into hard classified bone. The acoustic force enhances the differentiation of chondrocytes to boneforming osteoblast cells and the formation of a calcified collagenous extracellular matrix [84, 85]. Targeted drug delivery remains to be an unmet challenge as well. Ultrasound is used regularly in the clinical setting for topical drug delivery and is considered a viable option [86-88]. The acoustic force and diathermic effects of ultrasound can increase the permeability of skin layers and push through small and large drug molecules. SAM treatment for sonophoresis, specifically for drugs associated with 


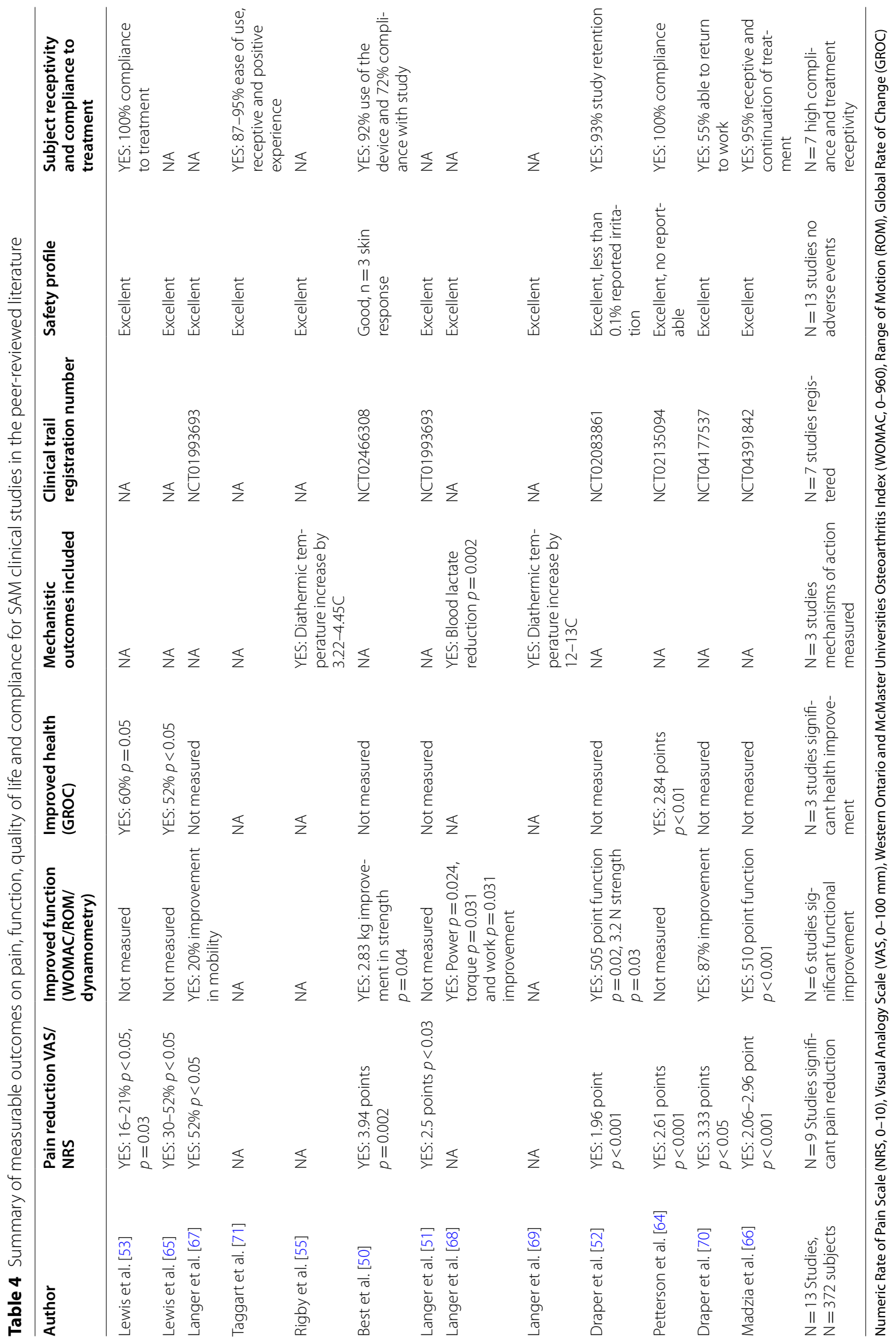



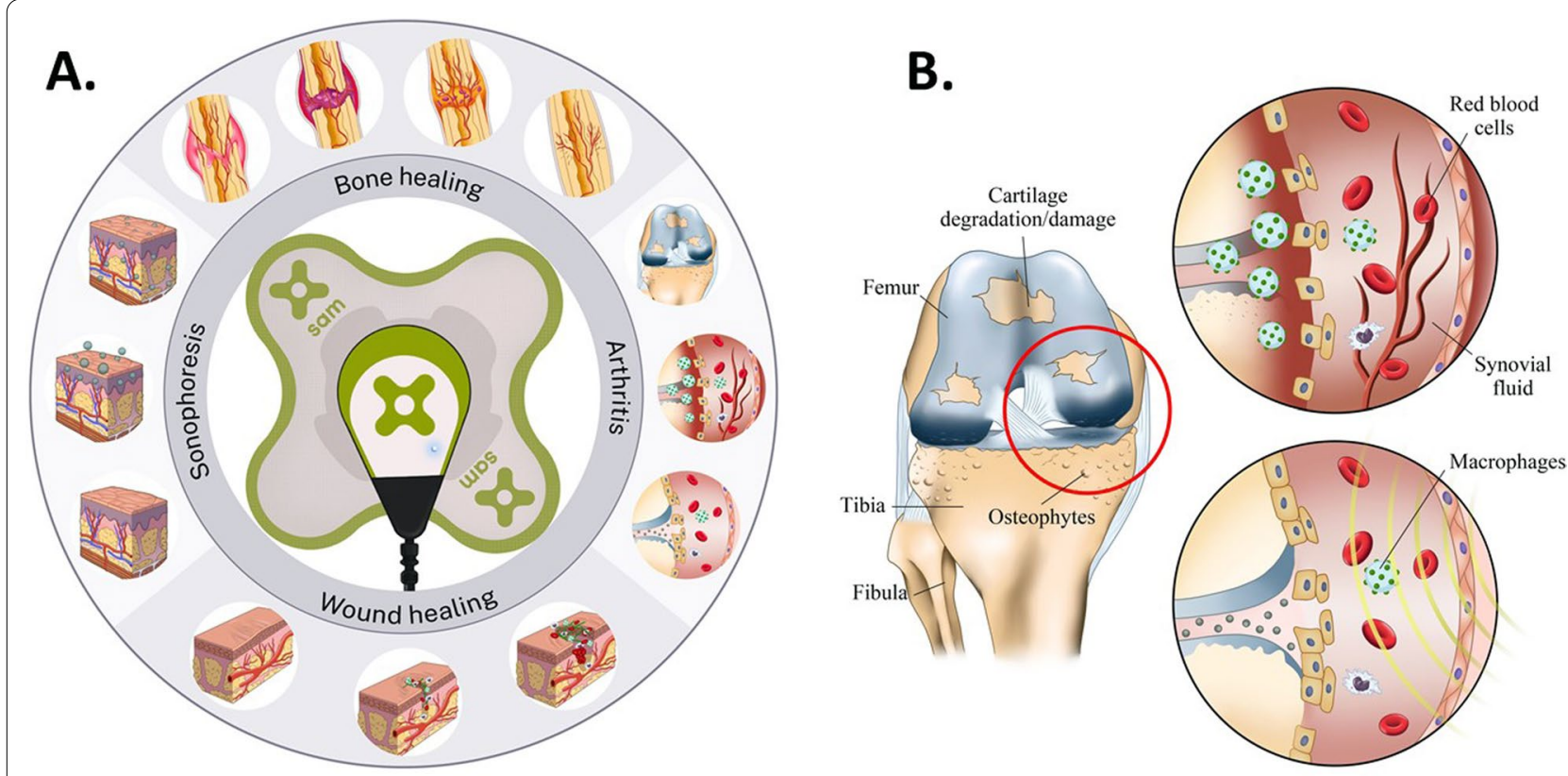

Fig. 6 The future application of SAM treatment. A Ultrasound thermal and acoustic properties can improve local drug delivery, improve wound and bone healing and reduce arthritis progression. B Ultrasound treatment may reduce the progression of osteoarthritis by reducing the rate of osteophyte formation and inflammatory cell activation

pain reduction, further enhances the pain management of SAM therapy, as shown by Madiza et al. 2020 [66]. Delayed or chronic wound healing due to type I or II diabetes is potentially another area of interest for applying SAM therapy [89-91]. The acoustic force can potentially enhance the blood flow, oxygenation, cellular migration, and formation of new extracellular to close the open wound and expedite the healing process [91].

\section{Limitations}

Although the systematic review focused on Sustained Acoustic Medicine (SAM) for the treatment of musculoskeletal injuries, it is possible that other relevant studies using similar treatment parameters $(3 \mathrm{MHz}$ ultrasound at $1.3 \mathrm{~W}$ ) are available in the scientific literature to further aggregate and synthesize the clinical literature. This limitation was beyond the scope of this research but could be considered in a future analysis paying close attention to time, duration, dose delivered and regularity of ultrasound treatment. The literature search strategy we employed found 13 relevant articles specific to SAM that are more than other past reviews on Sustained Acoustic Medicine ever, it is possible that some relevant studies were missed that were not available in English language or those in the grey literature which are emerging on this new therapeutic treatment [79, 92, 93]. Additionally, several of the outcome variables used in the studies differed in both measure, physical location on the body, condition being treated and control group which limited the scope of meta-analysis. However, we are confident that the most relevant clinical studies on SAM have been identified, and the categorical grouping of the studies supports the inferences drawn.

\section{Conclusions}

This systematic review and meta-analysis reported the current evidence for Sustained Acoustic Medicine on musculoskeletal injuries and chronic pain. SAM, a novel mechanobiological treatment, is clinically effective at reducing pain, improving overall health quality, generating deep therapeutic heat, and increasing mobility leading to a better-quality life and return to daily activities. The prescription home use treatment has excellent safety, usability and satisfaction characteristics for patients, and may be considered a good non-pharmacological and noninvasive treatment option in musculoskeletal injuries.

\section{Acknowledgements}

The authors would like to thank Professor Dominic Klyve from the Department of Mathematics, Central Washington University, Washington, United States for biostatistical meta-analysis support of this research.

\section{Authors' contributions}

SW, AU, and TB contributed equally towards research, data analysis and writing of the manuscript. All the authors read and approved the final manuscript. 


\section{Availability of data and materials}

All data generated and analyzed during this study are included in this published article.

\section{Declarations}

\section{Competing interests}

The authors declare no competing interests.

\section{Author details}

${ }^{1}$ James A. Haley Veteran Administration Hospital, Tampa, FL, USA. ${ }^{2}$ UHealth Sports Medicine Institute, University of Miami, Coral Gables, FL, USA.

Received: 5 October 2021 Accepted: 18 November 2021 Published online: 18 December 2021

\section{References}

1. Airaksinen O, Brox Jl, Cedraschi C, Hildebrandt J, Klaber-Moffett J, Kovacs $F$, et al. European guidelines for the management of chronic nonspecific low back pain. Eur Spine J. 2006;15(2):S192-300.

2. El-Tallawy SN, Nalamasu R, Salem GI, LeQuang JAK, Pergolizzi JV, Christo PJ. Management of musculoskeletal pain: an update with emphasis on chronic musculoskeletal pain. Pain Ther. 2021;10(1):181-209.

3. Brief report: Morbidity burdens attributable to illnesses and injuries in deployed (per Theater Medical Data Store [TMDS]) compared to nondeployed (per Defense Medical Surveillance System [DMSS]) settings, active component, US Armed Forces, 2010. MSMR. 2011;18(11):14-5.

4. Yelin E, Weinstein S, King T. The burden of musculoskeletal diseases in the United States. Semin Arthritis Rheum. 2016;46(3):259-60.

5. Yelin E, Weinstein S, King T. An update on the burden of musculoskeletal diseases in the U.S. Semin Arthritis Rheum. 2019;49(1):1-2.

6. Li Y, Wei X, Zhou J, Wei L. The age-related changes in cartilage and osteoarthritis. Biomed Res Int. 2013;2013:916530.

7. Aicale R, Tarantino D, Maffulli N. Overuse injuries in sport: a comprehensive overview. J Orthop Surg Res. 2018;13(1):309.

8. Aigner T, Gerwin N. Growth plate cartilage as developmental model in osteoarthritis research-potentials and limitations. Curr Drug Targets. 2007:8(2):377-85.

9. Gerwin RD. Classification, epidemiology, and natural history of myofascial pain syndrome. Curr Pain Headache Rep. 2001;5(5):412-20.

10. Gerwin RD, Dommerholt J, Shah JP. An expansion of Simons' integrated hypothesis of trigger point formation. Curr Pain Headache Rep. 2004;8(6):468-75.

11. Goldfarb CA, Puri SK, Carlson MG. Diagnosis, treatment, and return to play for four common sports injuries of the hand and wrist. J Am Acad Orthop Surg. 2016;24(12):853-62.

12. Mense SGR. Muscle pain: understanding the mechanisms; 2010.

13. Lauber B, Konig D, Gollhofer A, Centner C. Isometric blood flow restriction exercise: acute physiological and neuromuscular responses. BMC Sports Sci Med Rehabil. 2021;13(1):12

14. Koechlin $\mathrm{H}$, Whalley B, Welton NJ, Locher C. The best treatment option(s) for adult and elderly patients with chronic primary musculoskeletal pain: a protocol for a systematic review and network meta-analysis. Syst Rev. 2019;8(1):269.

15. American Society of Anesthesiologists Task Force on Chronic Pain M, American Society of Regional A, Pain M. Practice guidelines for chronic pain management: an updated report by the American Society of Anesthesiologists Task Force on Chronic Pain Management and the American Society of Regional Anesthesia and Pain Medicine. Anesthesiology. 2010; 112(4):810-33.

16. Dijkmans BA, Janssen M, Vandenbroucke JP, Lamers CB. NSAID-associated upper gastrointestinal damage in patients with rheumatoid arthritis. Scand J Gastroenterol Suppl. 1995;212:105-8.

17. Baranowski DC, Buchanan B, Dwyer HC, Gabriele JP, Kelly S, Araujo JA. Penetration and efficacy of transdermal NSAIDs in a model of acute joint inflammation. J Pain Res. 2018;11:2809-19.
18. Harirforoosh S, Asghar W, Jamali F. Adverse effects of nonsteroidal antiinflammatory drugs: an update of gastrointestinal, cardiovascular and renal complications. J Pharm Pharm Sci. 2013;16(5):821.

19. Suleyman H, Demircan B, Karagoz Y. Anti-inflammatory and side effects of cyclooxygenase inhibitors. Pharmacol Rep. 2007;59(3):247-58.

20. Kata V, Novitch MB, Jones MR, Anyama BO, Helander EM, Kaye AD. Opioid addiction, diversion, and abuse in chronic and cancer pain. Curr Opin Support Palliat Care. 2018;12(2):124-30.

21. Owusu Obeng A, Hamadeh I, Smith M. Review of opioid pharmacogenetics and considerations for pain management. Pharmacotherapy. 2017;37(9):1105-21.

22. Sullivan MD, Robinson JP. Antidepressant and anticonvulsant medication for chronic pain. Phys Med Rehabil Clin N Am. 2006;17(2):381-400.

23. UhI RL, Roberts TT, Papaliodis DN, Mulligan MT, Dubin AH. Management of chronic musculoskeletal pain. J Am Acad Orthop Surg. 2014;22(2):101-10.

24. Wright ME, Rizzolo D. An update on the pharmacologic management and treatment of neuropathic pain. JAAPA. 2017:30(3):13-7.

25. Hepner S, Claxton R. Anti-epileptic drugs for pain \#271. J Palliat Med. 2013;16(7):799-800.

26. Trinh K, Graham N, Gross A, Goldsmith C, Wang E, Cameron I, et al. Acupuncture for neck disorders. Spine Phila Pa 1976. 2007;32(2):236-43.

27. Cheatle MD, Shmuts $R$. The risk and benefit of benzodiazepine use in patients with chronic pain. Pain Med. 2015;16(2):219-21.

28. Takkouche B, Montes-Martinez A, Gill SS, Etminan M. Psychotropic medications and the risk of fracture: a meta-analysis. Drug Saf. 2007:30(2):171-84.

29. van Tulder MW, Koes BW, Bouter LM. Conservative treatment of acute and chronic nonspecific low back pain. A systematic review of randomized controlled trials of the most common interventions. Spine Phila Pa 1976. 1997:22(18):2128-56.

30. Abenhaim L, Rossignol M, Valat JP, Nordin M, Avouac B, Blotman F, et al. The role of activity in the therapeutic management of back pain. Report of the international Paris task force on back pain. Spine Phila Pa 1976. 2000;25(4 Suppl):1S-33S.

31. Patel K, Bakshi N, Freehill MT, Awan TM. Whole-body cryotherapy in sports medicine. Curr Sports Med Rep. 2019;18(4):136-40.

32. Swenson C, Sward L, Karlsson J. Cryotherapy in sports medicine. Scand J Med Sci Sports. 1996;6(4):193-200

33. French SD, Cameron M, Walker BF, Reggars JW, Esterman AJ. Superficial heat or cold for low back pain. Cochrane Database Syst Rev. 2006:1:CD004750.

34. Lehmann JF, Warren CG, Scham SM. Therapeutic heat and cold. Clin Orthop Relat Res. 1974;99:207-45.

35. Balthazard P, de Goumoens P, Rivier G, Demeulenaere P, Ballabeni P, Deriaz O. Manual therapy followed by specific active exercises versus a placebo followed by specific active exercises on the improvement of functional disability in patients with chronic non specific low back pain: a randomized controlled trial. BMC Musculoskelet Disord. 2012:13:162.

36. Machotka Z, Kumar S, Perraton LG. A systematic review of the literature on the effectiveness of exercise therapy for groin pain in athletes. Sports Med Arthrosc Rehabil Ther Technol. 2009;1(1):5.

37. Hynynen K, DeYoung D. Temperature elevation at muscle-bone interface during scanned, focused ultrasound hyperthermia. Int J Hyperthermia. 1988:4(3):267-79

38. Ahmed H-ASS, Ali OI, ElLaithy MHG. Continuous versus pulsed ultrasound on myofascial pain syndrome: Randomized single blind controlled trial. Int J Therap Rehabil Res. 2017;17(6):2.

39. Aiyer R, Noori SA, Chang KV, Jung B, Rasheed A, Bansal N, et al. Therapeutic ultrasound for chronic pain management in joints: a systematic review. Pain Med. 2019;21:1437-48.

40. Uddin SMZ, Komatsu DE. Therapeutic potential low-intensity pulsed ultrasound for osteoarthritis: pre-clinical and clinical perspectives. Ultrasound Med Biol. 2020:46(4):909-20.

41. Noori SA, Rasheed A, Aiyer R, Jung B, Bansal N, Chang KV, et al. Therapeutic ultrasound for pain management in chronic low back pain and chronic neck pain: a systematic review. Pain Med. 2020;21(7):1482-93.

42. Bohm E. Transcutaneous electrical nerve stimulation in chronic pain after peripheral nerve injury. Acta Neurochir (Wien). 1978;40(3-4):277-83. 
43. Cauthen JC, Renner EJ. Transcutaneous and peripheral nerve stimulation for chronic pain states. Surg Neurol. 1975;4(1):102-4.

44. Bergmann T, Maeder U, Fiebich M, Dickob M, Nattkemper TW, Anselmetti D. Categorization of two-photon microscopy images of human cartilage into states of osteoarthritis. Osteoarthritis Cartilage. 2013;21(8):1074-82.

45. Clijsen R, Brunner A, Barbero M, Clarys P, Taeymans J. Effects of lowlevel laser therapy on pain in patients with musculoskeletal disorders: a systematic review and meta-analysis. Eur J Phys Rehabil Med. 2017;53(4):603-10.

46. Kannan P. Management of myofascial pain of upper trapezius: a three group comparison study. Glob J Health Sci. 2012;4(5):46-52.

47. Morimoto Y, Saito A, Tokuhashi Y. Low level laser therapy for sports injuries. Laser Ther. 2013;22(1):17-20.

48. Zhang C, Xie Y, Luo X, Ji Q, Lu C, He C, et al. Effects of therapeutic ultrasound on pain, physical functions and safety outcomes in patients with knee osteoarthritis: a systematic review and meta-analysis. Clin Rehabil. 2016;30(10):960-71.

49. SAM 2.0 Home use approval, United States Food and Drug Administration, Medical Device Database, Accessed (9/1/2021) https://www.acces sdata.fda.gov/cdrh_docs/pdf19/K191568.pdf.

50. Best TM, Moore B, Jarit P, Moorman CT, Lewis GK. Sustained acoustic medicine: wearable, long duration ultrasonic therapy for the treatment of tendinopathy. Phys Sportsmed. 2015;43(4):366-74

51. Langer MD, Lewis GK, Jr. Sustained acoustic medicine: A novel long duration approach to biomodulation utilizing low intensity therapeutic ultrasound. Proc SPIE Int Soc Opt Eng 2015; 9467

52. Draper DO, Klyve D, Ortiz R, Best TM. Effect of low-intensity long-duration ultrasound on the symptomatic relief of knee osteoarthritis: a randomized, placebo-controlled double-blind study. J Orthop Surg Res. 2018;13(1):257.

53. Lewis GK Jr, Langer MD, Henderson CR Jr, Ortiz R. Design and evaluation of a wearable self-applied therapeutic ultrasound device for chronic myofascial pain. Ultrasound Med Biol. 2013;39(8):1429-39.

54. Lewis GHL, Lewis Sr GK, Ortiz Wearable long duration ultrasound therapy pilot study in rotator cuff tendinopathy. Proc Meet Acoust. 2013;19.

55. Rigby JH, Taggart RM, Stratton KL, Lewis GK Jr, Draper DO. Intramuscular heating characteristics of multihour low-intensity therapeutic ultrasound. J Athl Train. 2015;50(11):1158-64.

56. Qin YX, Hu M. Mechanotransduction in musculoskeletal tissue regeneration: effects of fluid flow, loading, and cellular-molecular pathways. Biomed Res Int. 2014;2014:863421.

57. Sato M, Nagata K, Kuroda S, Horiuchi S, Nakamura T, Karima M, et al. Lowintensity pulsed ultrasound activates integrin-mediated mechanotransduction pathway in synovial cells. Ann Biomed Eng. 2014;42(10):2156-63.

58. Babakhanian M, Yang L, Nowroozi B, Saddik G, Boodaghians L, Blount $P$, et al. Effects of low intensity focused ultrasound on liposomes containing channel proteins. Sci Rep. 2018;8(1):17250.

59. Goldberg JD, Chervenak FA, Lipman RA, Berkowitz RL. Antenatal sonographic diagnosis of arthrogryposis multiplex congenita. Prenat Diagn. 1986;6(1):45-9.

60. Hou CH, Lin J, Huang SC, Hou SM, Tang CH. Ultrasound stimulates NF-kappa B activation and iNOS expression via the Ras/Raf/MEK ERK signaling pathway in cultured preosteoblasts. J Cell Physiol. 2009;220(1):196-203.

61. de Gusmao CVB, Pauli JR, Saad MJA, Alves JM, Belangero WD. Lowintensity ultrasound increases FAK, ERK-1/2, and IRS-1 expression of intact rat bones in a noncumulative manner. Clin Orthop Relat R. 2010:468(4):1149-56.

62. Page MJ, McKenzie JE, Bossuyt PM, Boutron I, Hoffmann TC, Mulrow CD et al. The PRISMA 2020 statement: An updated guideline for reporting systematic reviews. Int J Surg. 2021;88:105906.

63. Downs $\mathrm{SH}$, Black N. The feasibility of creating a checklist for the assessment of the methodological quality both of randomised and nonrandomised studies of health care interventions. J Epidemiol Commun Health. 1998;52(6):377-84

64. Petterson S, Plancher K, Klyve D, Draper D, Ortiz R. Low-intensity continuous ultrasound for the symptomatic treatment of upper shoulder and neck pain: a randomized, double-blind placebo-controlled clinical trial. J Pain Res. 2020;13:1899-900

65. Lewis G, Hernandez L, Ortiz R. Wearable long duration ultrasound therapy pilot study in rotator cuff tendinopathy. 2013;19:075103.
66. Madzia A, Agrawal C, Jarit P, Petterson S, Plancher K, Ortiz R. Sustained acoustic medicine combined with a diclofenac ultrasound coupling patch for the rapid symptomatic relief of knee osteoarthritis: multi-site clinical efficacy study. Open Orthop J. 2020;14:176-85.

67. Langer MD, Levine V, Taggart R, Lewis GK, Hernandez L, Ortiz R. Pilot Clinical Studies of Long Duration, Low Intensity Therapeutic Ultrasound for Osteoarthritis. In: Proceedings IEEE annual northeast bioengineering conference 2014; 2014

68. Langer MD, Byrne HK, Henry T, et al. The effect of low intensity wearable ultrasound on blood lactate and muscle performance after high intensity resistance exercise. J Exerc Physiol. 2017;20:14.

69. Langer MD, et al, editor Skin temperature increase mediated by wearable, long duration, low-intensity therapeutic ultrasound. In: AIP conference proceedings; 2017.

70. Draper DO, Wells A, Wilk K. Efficacy of sustained acoustic medicine as an add-on to traditional therapy in treating sport-related injuries: case reports. Glob J Orthop Res. 2020;2(4):545

71. Taggart R, Langer MD, Lewis GK Jr. Human factors engineering and testing for a wearable, long duration ultrasound system self-applied by an end user. Annu Int Conf IEEE Eng Med Biol Soc. 2014;2014:554-7.

72. Desai MJ, Saini V, Saini S. Myofascial pain syndrome: a treatment review. Pain Ther. 2013;2(1):21-36.

73. Oren TW, Botolin S, Williams A, Bucknell A, King KB. Arthroplasty in veterans: analysis of cartilage, bone, serum, and synovial fluid reveals differences and similarities in osteoarthritis with and without comorbid diabetes. J Rehabil Res Dev. 2011;48(10):1195-210.

74. Pilling RW, Moulder E, Allgar V, Messner J, Sun Z, Mohsen A. Patellar resurfacing in primary total knee replacement: a meta-analysis. J Bone Joint Surg Am. 2012;94(24):2270-8.

75. Masterson J, Kluge B, Burdette AGL Sr. Sustained acoustic medicine; sonophoresis for nonsteroidal anti-inflammatory drug delivery in arthritis. Ther Deliv. 2020;11(6):363-72.

76. Petterson S, Plancher K, Klyve D, Draper D, Ortiz R. Low-intensity continuous ultrasound for the symptomatic treatment of upper shoulder and neck pain: a randomized, double-blind placebo-controlled clinical trial. J Pain Res. 2020;13:1277-87.

77. Best TM, Petterson S, Plancher K. Sustained acoustic medicine as a nonsurgical and non-opioid knee osteoarthritis treatment option: a health economic cost-effectiveness analysis for symptom management. J Orthop Surg Res. 2020;15(1):481.

78. David O, Draper TB. Critical survey and panel review of sustained acoustic medicine in the treatment of sports-related musculoskeletal injuries by professional sports athletic trainers. Curr Orthop Pract. 2021;32(2):7.

79. Uddin SMZ, Komatsu DE, Motyka T, Petterson S. Low-intensity continuous ultrasound therapies-a systemic review of current state-of-the-art and future perspectives. J Clin Med. 2021;10(12):2698.

80. Chung Jl, Barua S, Choi BH, Min BH, Han HC, Baik EJ. Anti-inflammatory effect of low intensity ultrasound (LIUS) on complete Freund's adjuvant-induced arthritis synovium. Osteoarthr Cartil. 2012;20(4):314-22.

81. Uddin SM, Richbourgh B, Ding Y, Hettinghouse A, Komatsu DE, Qin YX, et al. Chondro-protective effects of low intensity pulsed ultrasound. Osteoarthr Cartil. 2016:24(11):1989-98.

82. Gold SM, Wasserman R. Preliminary results of tibial bone transports with pulsed low intensity ultrasound (Exogen). J Orthop Trauma. 2005;19(1):10-6

83. Higgins A, Glover M, Yang Y, Bayliss S, Meads C, Lord J. EXOGEN ultrasound bone healing system for long bone fractures with non-union or delayed healing: a NICE medical technology guidance. Appl Health Econ Health Policy. 2014;12(5):477-84

84. Craig JG, Jacobson JA, Moed BR. Ultrasound of fracture and bone healing. Radiol Clin North Am. 1999;37(4):737-51.

85. El-Mowafi H, Mohsen M. The effect of low-intensity pulsed ultrasound on callus maturation in tibial distraction osteogenesis. Int Orthop. 2005;29(2):121-4.

86. Bekeredjian R, Chen S, Frenkel PA, Grayburn PA, Shohet RV. Ultrasoundtargeted microbubble destruction can repeatedly direct highly specific plasmid expression to the heart. Circulation. 2003;108(8):1022-6.

87. Feiszthuber H, Bhatnagar S, Gyongy M, Coussios CC. Cavitationenhanced delivery of insulin in agar and porcine models of human skin. Phys Med Biol. 2015;60(6):2421-34. 
88. Kost J. Ultrasound-assisted insulin delivery and noninvasive glucose sensing. Diabetes Technol Ther. 2002;4(4):489-97.

89. Ennis WJ, Valdes W, Gainer M, Meneses P. Evaluation of clinical effectiveness of MIST ultrasound therapy for the healing of chronic wounds. Adv Skin Wound Care. 2006;19(8):437-46.

90. Ikai H, Tamura T, Watanabe T, Itou M, Sugaya A, Iwabuchi S, et al. Lowintensity pulsed ultrasound accelerates periodontal wound healing after flap surgery. J Periodontal Res. 2008;43(2):212-6.

91. Zhou S, Schmelz A, Seufferlein T, Li Y, Zhao J, Bachem MG. Molecular mechanisms of low intensity pulsed ultrasound in human skin fibroblasts. J Biol Chem. 2004;279(52):54463-9.

92. Best TM, Wilk KE, Moorman CT, Draper DO. Low intensity ultrasound for promoting soft tissue healing: a systematic review of the literature and medical technology. Intern Med Rev Wash DC. 2016;2(11):271.

93. Daniels S, Santiago G, Cuchna J, Van Lunen B. The effects of low-intensity therapeutic ultrasound on measurable outcomes: a critically appraised topic. J Sport Rehabil. 2018;27(4):390-5.

\section{Publisher's Note}

Springer Nature remains neutral with regard to jurisdictional claims in published maps and institutional affiliations.

- fast, convenient online submission

- thorough peer review by experienced researchers in your field

- rapid publication on acceptance

- support for research data, including large and complex data types

- gold Open Access which fosters wider collaboration and increased citations

- maximum visibility for your research: over $100 \mathrm{M}$ website views per year

At BMC, research is always in progress.

Learn more biomedcentral.com/submissions 